\title{
Marine lipids overview: markets, regulation, and the value chain
}

\author{
Adam ISMAIL \\ Global Organization for EPA and DHA Omega-3s, \\ 1075 Hollywood Ave, \\ Salt Lake City, \\ UT 84105, \\ United States \\ <adam@goedomega3.com>
}

\begin{abstract}
Scientific advances have propelled the market for EPA and DHA omega-3s to high growth rates and a significant size for consumer products by increasing media exposure and authoritative recommendations on the benefits of omega-3s. There are no signs that the rate of scientific advancement is slowing, which should continue to support the market and continue to lead to greater penetration in sectors like functional foods. The industry has acted proactively to set high standards to enable the market's growth, and with significant investments into new sources of EPA and DHA, these standards will become even more important. Significant structural changes in the supply side of the market appear to be on the horizon both from the new sources and from the increasing demand for crude fish oils reaching the limits of available supply. Ultimately, economics will decide how the market evolves over the next 5 to 10 years.
\end{abstract}

Key words: omega-3, marine lipids, market size, regulations, supply and demand

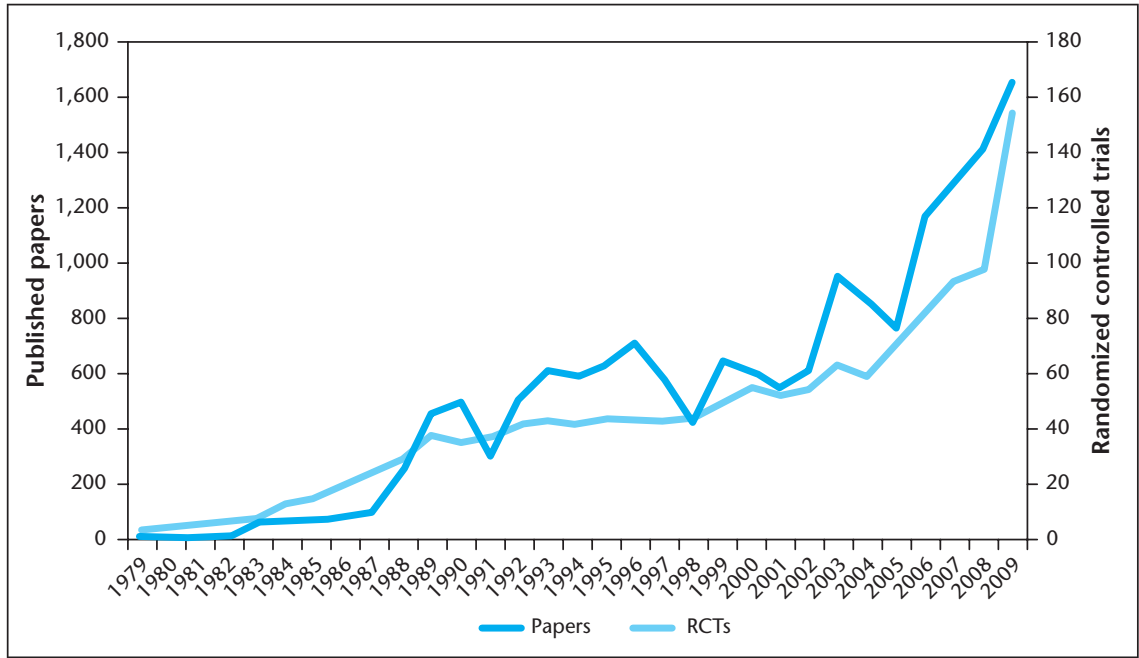

Figure 1. EPA/DHA omega-3 papers published, 1979-2009.

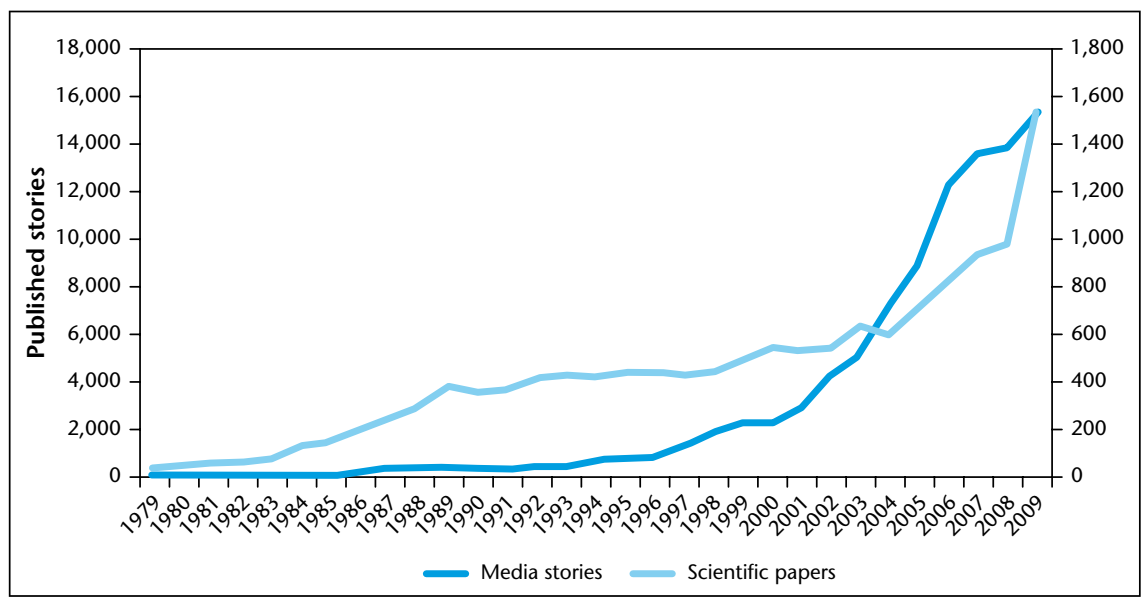

Figure 2. Media stories published on omega-3s, 1979-2009.
The market for products containing EPA and DHA omega-3s has grown rapidly in recent years, more than quadrupling in size since 2001. GOED and Frost \& Sullivan estimate that globally more than 86,000 tons of finished oils containing EPA and DHA were consumed in 2009. This translates into nearly US\$13.1 billion in consumer expenditures on long-chain omega-3 products in multiple applications, and approximately US\$1.29 billion in ingredient sales of refined oils and concentrated omega-3s (Frost \& Sullivan, 2010).

The most common sources of EPA and DHA for consumers are often thought to be seafood and fish oil supplements, but the market has evolved significantly. Today, $17 \%$ of the global consumption of the fats comes from fortified foods, another $12 \%$ in infant and clinical nutrition, and $6 \%$ come even from pharmaceuticals (Frost \& Sullivan, 2010). In fact, last year, the first "blockbuster" drug milestone was reached with sales of the Lovaza/Omacor product from Pronova reaching US\$1 billion in sales (Pronova Biopharma, 2010).

The growth in the body of science has driven the growth in sales of omega-3s. While data is not available in all geographies, sales of omega-3 dietary supplements in the US are correlated with the number of new scientific papers published each year on EPA and DHA, as can be seen in figure 1. In fact, the correlation is so strong, the R-squared statistic indicates that the number of new papers published explains $92 \%$ of the sales increase each year. This is important for predicting future market growth because a search of the PubMed database shows that the pace of new publication is actually increasing, 
and in 2009 reached 1500 new papers from only 500 papers published in 2001.

We hypothesize that the mechanism by which new scientific publication leads to increased market growth of omega-3s is by the new papers leading to increased media exposure in the form of stories in consumer media outlets. This effect is both short-term and long-term in that consumer media stories are immediately written when new research comes out, but the steady flow of new publication also leads to a greater share of mind from consumer health editors, as can be seen in figure 2 . Additionally, the new volumes of research being published on the scale of omega-3s also leads to greater recognition by regulatory authorities in the form of new health claims being authorized and intake recommendations being established. While this effect logically lags the media effect in terms of market impact, it also leads to additional media exposure both from national public health campaigns and from the newsworthiness of new health recommendations being established.

Indeed, consumer awareness of omega-3s has increased steadily over time. According to multiple sources, only $55 \%$ of American consumers had heard of omega-3s in 2001, but by 2008, the figure had nearly reached $88 \%$. Research from Leatherhead has shown that awareness in the UK, Spain, Italy, and Germany actually exceeds $90 \%$ of the population. Ironically, France has the lowest recognition of the major European economies, despite having some of

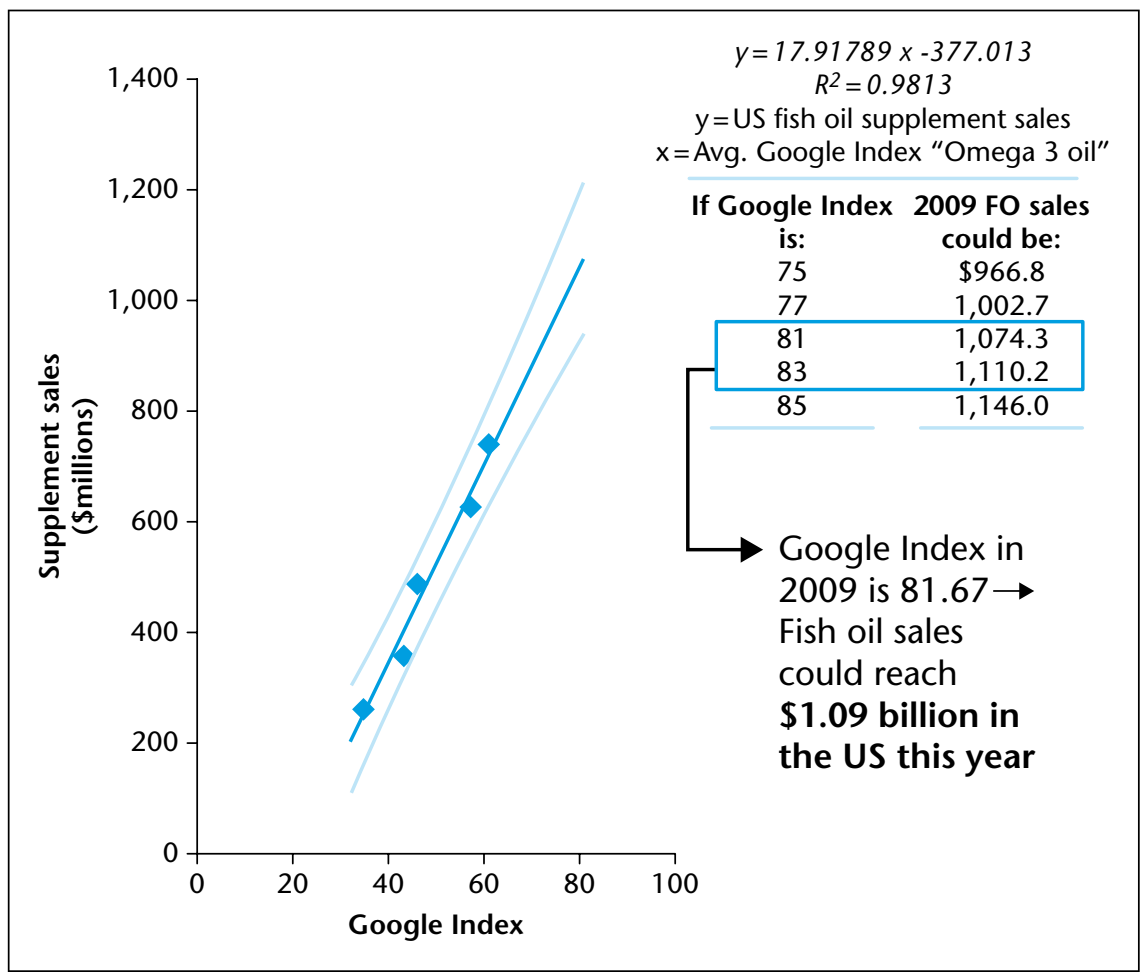

Figure 3. Correlation between US Coogle searches for omega-3 oil and fish oil supplement sales (2004-2008).

the most progressive intake recommendations in the world (Leatherhead Food Research, 2008).

Consumer awareness does not necessarily indicate consumer interest, however. There is data, though, that may shed light on whether or not increased consumer interest does translate into increased market growth. Google search volume on omega- $3 \mathrm{~s}$ in the US has steadily increased since 2004, when Google began pub-

\begin{tabular}{|c|c|c|c|c|c|c|c|c|}
\hline & \multirow[b]{2}{*}{$\begin{array}{c}\text { EC } \\
\text { Regulations }\end{array}$} & \multirow[b]{2}{*}{$\begin{array}{l}\text { Eur Pharm } \\
\text { Fish Oils }\end{array}$} & \multirow[b]{2}{*}{ USP Fish Oils } & \multirow[b]{2}{*}{$\begin{array}{c}\text { GOED } \\
\text { Voluntary } \\
\text { Monograph }\end{array}$} & \multirow[b]{2}{*}{$\begin{array}{l}\text { Australia } \\
\text { DRAFT } \\
\text { Guidance }\end{array}$} & \multicolumn{3}{|c|}{ Specific to Concentrates } \\
\hline & & & & & & $\begin{array}{c}\text { Eur Pharm } \\
\text { Omega-3 TGs }\end{array}$ & $\begin{array}{c}\text { Eur Pharm } \\
\text { Omega-3 EEs } \\
60 \%\end{array}$ & $\begin{array}{c}\text { Eur Pharm } \\
\text { Omega-3 EEs } \\
90 \%\end{array}$ \\
\hline \multicolumn{9}{|l|}{ Quality Limits } \\
\hline p-Anisidine Value, $\max$ & $\mathrm{N} / \mathrm{A}$ & 30.0 & 20.0 & 20.0 & 30.0 & 30.0 & 20.0 & 20.0 \\
\hline Peroxide Value, $\max$ & $\mathrm{N} / \mathrm{A}$ & 10.0 & 5.0 & 5.0 & 10.0 & 10.0 & 10.0 & 10.0 \\
\hline $\begin{array}{l}\text { Unsaponifiable Matter, } \\
\max \end{array}$ & $\mathrm{N} / \mathrm{A}$ & $1.5 \%$ & $1.5 \%$ & N/A & $1.5 \%$ & $\mathrm{~N} / \mathrm{A}$ & $\mathrm{N} / \mathrm{A}$ & $\mathrm{N} / \mathrm{A}$ \\
\hline Stearin, $\max$ & $\mathrm{N} / \mathrm{A}$ & $10 \mathrm{ml}$ & $10 \mathrm{ml}$ & $\mathrm{N} / \mathrm{A}$ & $10 \mathrm{ml}$ & $\mathrm{N} / \mathrm{A}$ & $\mathrm{N} / \mathrm{A}$ & $\mathrm{N} / \mathrm{A}$ \\
\hline TOTOX, max & $\mathrm{N} / \mathrm{A}$ & $\mathrm{N} / \mathrm{A}$ & 26 & 26 & $\mathrm{~N} / \mathrm{A}$ & $\mathrm{N} / \mathrm{A}$ & $\mathrm{N} / \mathrm{A}$ & $\mathrm{N} / \mathrm{A}$ \\
\hline \multicolumn{9}{|l|}{ Safety Limits } \\
\hline $\begin{array}{l}\text { Dioxins and Furans, } \\
\text { max pg WHO-PCDD/F- } \\
\text { TEQ/kg }\end{array}$ & $2.0^{\ddagger}$ & $\mathrm{N} / \mathrm{A}$ & 2.0 & 2.0 & 2.0 & $\mathrm{~N} / \mathrm{A}$ & $\mathrm{N} / \mathrm{A}$ & $\mathrm{N} / \mathrm{A}$ \\
\hline $\begin{array}{l}\text { Dioxin-like PCBs, max } \\
\mathrm{pg} \text { WHO-TEQ/kg }\end{array}$ & $8.0-10.0^{\ddagger}$ & $\mathrm{N} / \mathrm{A}$ & $8.0-10.0$ & 3.0 & $8.0-10.0$ & $\mathrm{~N} / \mathrm{A}$ & $\mathrm{N} / \mathrm{A}$ & $\mathrm{N} / \mathrm{A}$ \\
\hline PCBs, $\max \mathrm{mg} / \mathrm{kg}$ & $\mathrm{N} / \mathrm{A}$ & $\mathrm{N} / \mathrm{A}$ & $\mathrm{N} / \mathrm{A}$ & 0.09 & $\mathrm{~N} / \mathrm{A}$ & $\mathrm{N} / \mathrm{A}$ & $\mathrm{N} / \mathrm{A}$ & $\mathrm{N} / \mathrm{A}$ \\
\hline Lead $(\mathrm{Pb})$, max mg/kg & $0.1^{\ddagger}$ & $\mathrm{N} / \mathrm{A}$ & 0.1 & 0.1 & 0.5 & $\mathrm{~N} / \mathrm{A}$ & $\mathrm{N} / \mathrm{A}$ & $\mathrm{N} / \mathrm{A}$ \\
\hline Arsenic (As), max mg/kg & $\mathrm{N} / \mathrm{A}$ & $\mathrm{N} / \mathrm{A}$ & 0.1 & 0.1 & 1.0 & $\mathrm{~N} / \mathrm{A}$ & $\mathrm{N} / \mathrm{A}$ & $\mathrm{N} / \mathrm{A}$ \\
\hline $\begin{array}{l}\text { Mercury }(\mathrm{Hg}), \max \\
\mathrm{mg} / \mathrm{kg}\end{array}$ & $\mathrm{N} / \mathrm{A}$ & $\mathrm{N} / \mathrm{A}$ & 0.1 & 0.1 & 0.5 & $\mathrm{~N} / \mathrm{A}$ & $\mathrm{N} / \mathrm{A}$ & $\mathrm{N} / \mathrm{A}$ \\
\hline $\begin{array}{l}\text { Cadmium (Cd), } \max \\
\mathrm{mg} / \mathrm{kg}\end{array}$ & $\mathrm{N} / \mathrm{A}$ & N/A & 0.1 & 0.1 & 0.5 & $\mathrm{~N} / \mathrm{A}$ & $\mathrm{N} / \mathrm{A}$ & $\mathrm{N} / \mathrm{A}$ \\
\hline \multicolumn{9}{|c|}{ † European Commission Directive 2006/141/EC (Eur Commission, 2006) } \\
\hline \multicolumn{9}{|c|}{ \#uropean Commission Regulation 1881/2006 (Eur Commission, 2006) } \\
\hline \multicolumn{9}{|c|}{ Note: Red text denotes strictest requirement } \\
\hline N/A: Not applicable & & & & & & & & \\
\hline
\end{tabular}

Figure 4. Quality specifications and regulations related to omega-3 oils. 
lishing its search data for public consumption. Indeed, searches for omega-3 terms correlate to omega-3 dietary supplement sales with an R-squared statistic of 0.98 using data through 2008 , as is shown in figure 3 . In fact, using this relationship to forecast 2009 sales indicates that sales of omega-3 supplements actually exceeded US\$1 billion last year.

While the market has grown on the back of science, there are variables common in consumer products that could threaten to decouple this relationship. The industry has been proactive in trying to prevent many of these events by collaborating over eight years ago to establish minimum quality standards based on the strictest aspects of regulations from geographies around the world, as is shown in figure 4. The industry's voluntary adoption of these standards has led to increased globalization of supply and prevented any significant food safety incidents like those that have affected other nutraceutical markets.

The effect of the strong market growth in traditional categories has been the incorporation of EPA and DHA into other categories like functional foods. The early market for EPA and DHA functional foods was dominated by products like spreads and yogurts that are friendlier to lipids needing protection from oxidative factors. However, the technological advances have moved the market forward greatly, and EPA and DHA can now be found in canned foods, baked goods, soft drinks, and confections, and in dozens of other food categories.
More importantly, this has been accomplished at higher dosages than are commonly perceived. In fact, there are some baked goods that have been fortified with omega- 3 dosages at levels equivalent to 10 fish oil capsules. Many authoritative bodies have begun to recommend that consumers should get a minimum of $250 \mathrm{mg}$ of EPA and DHA per day, and the high levels of fortification that are now achievable make it relatively easy to reach these dietary targets through fortified foods, as can be seen in figure 5.

Furthermore, multiple omega-3 functional foods have reached high levels of commercial success, which is a challenge for functional foods in general. The successes of the Weston Tip Top breads in Australia and the PULEVA

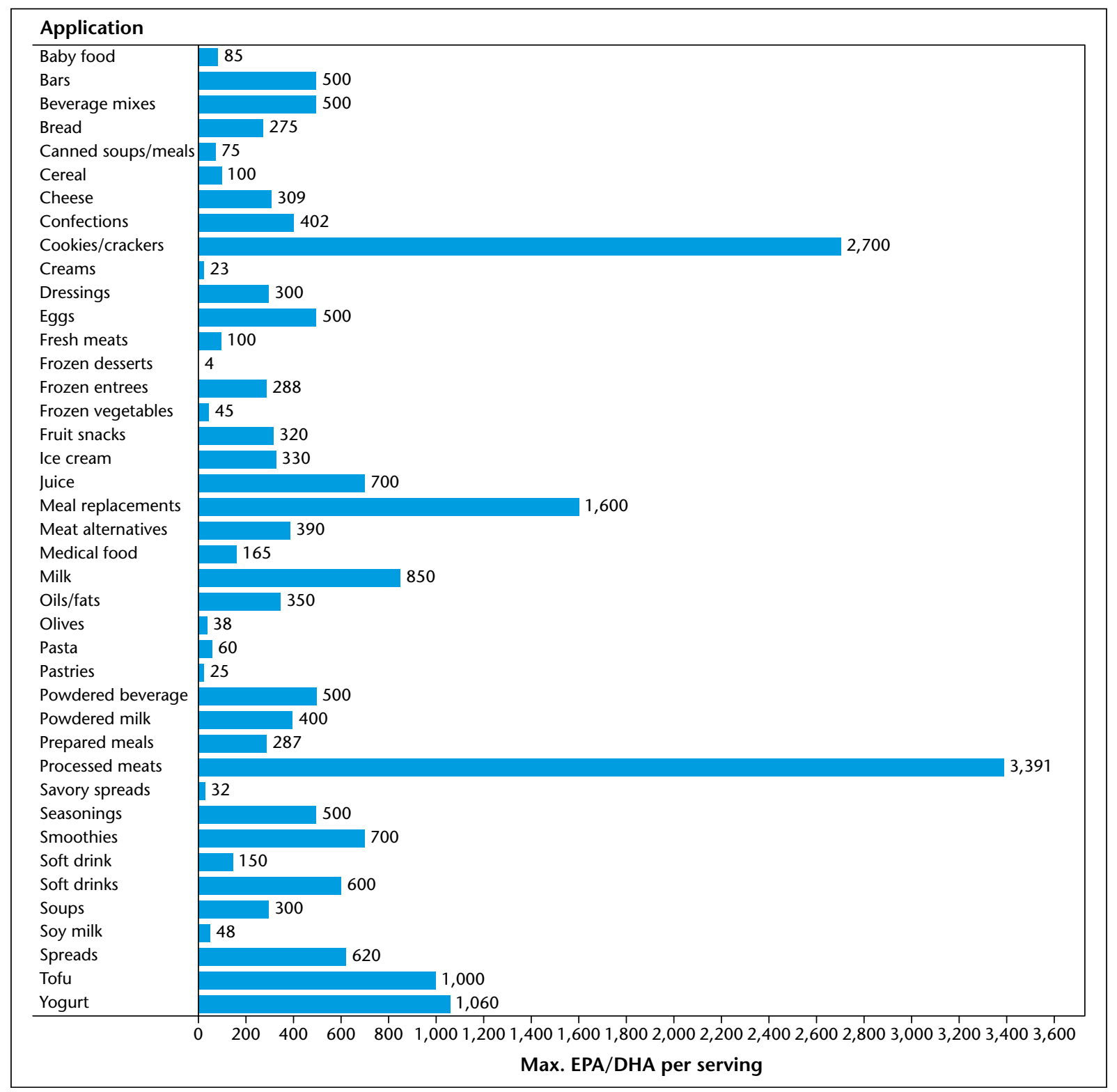

Figure 5. Highest EPA and DHA dosages achieved in commercial foods by application. 
milks in Spain are well known, with sales exceeding the equivalent of US\$1.7 billion per year, adjusted for population differences and purchasing power parity in the respective countries. However, according to GOED's estimates, there are many further successes that have seen sales exceed the equivalent of $\$ 50$ million in US sales in their respective countries, including the Resala sausages by Maruha in Japan, Danino yogurts in Canada, Minute Maid Enhanced juices in the United States, and the Smartfish juices in Norway.

Another function of the market growth has been the commercialization of new sources of EPA and DHA. Fish is the most recognized source of the fatty acids by consumers, but algae have been used for nearly two decades to produce oils high in DHA. There is currently work being conducted to commercialize algal sources that also contain high levels of EPA, and now a fungal source of EPA has also been launched commercially. In addition, more marine sources are being commercialized as well, including krill oils, green lipped mussel extracts, and squid oils. Economics is a key driving factor in the success of each source, so significant investments have been made into genetically modified oilseeds capable of producing long-chain omega-3s. No genetically modified plant sources are fully commercial yet, but the prospect of oilseed economics being introduced into the market could change the landscape dramatically.

Even without the prospect of alternative sources being introduced, there are also structural changes on the horizon in the fish oil supply sector. The most widely used species of fish for omega-3 oils are the ones with the highest levels of EPA and DHA, which are largely the South American anchovy fisheries that contain approximately $30 \%$ EPA+DHA content. The 86,000 tons of refined fish oils being consumed in the world actually equates to approximately 130,000 metric tons of crude fish oils due to yield losses, according to GOED's estimates. The challenge is that the South American fisheries are typically capable of supplying approximately 300,000 metric tons of oils in any given year based on the catch allowed under Peruvian regulations to ensure a sustainable fishery. This means that if the market continues growing as fast as it has in recent years, then the available supply of oils from the South American anchovy fishery will not be sufficient to supply the demand for all omega-3 applications by as early as 2013. The implication of this is that the more price-sensitive applications for omega-3 oils, like pet foods and dietary supplements, will be forced to find other sources of EPA and DHA while the least price-sensitive categories, like pharmaceuticals, will be forced to pay more for oil but will still have access to supply.

\section{REFERENCES}

Frost \& Sullivan. Frost \& Sullivan and the Global Organization for EPA and DHA Omega-3 Global Overview of the Marine and Algal Oil EPA and DHA Omega-3 Ingredients Market. Chicago, 2010.

Leatherhead Food Research. Omega-3 - Fad or Future? Surrey: Leatherhead Food Research, 2008.

Pronova Biopharma. (n.d.). Home Page. Retrieved June 30, 2010, from Pronova Biopharma Web Site: http://www.pronova.com 